\title{
Effects of Solvent Polarity on the Reaction of Aldehydes and Ketones with a Hydrazide Bound Scavenger Resin
}

Alline V. B. de Oliveira, Vinicius Kartnaller, Claudio Costa Neto, João Cajaiba*

Universidade Federal do Rio de Janeiro (UFRJ), Instituto de Química, Polo de Xistoquímica, Rua Hélio de Almeida 40, Cidade Universitária, Rio de Janeiro, RJ Brasil. ZIP CODE: 21941614 - Phone/Fax: 552125602299

* Corresponding author. Tel.: +55 21 25900990; fax: +55 2125602299.

E-mail address: cajaiba@iq.ufrj.br

\section{Comparison between solvents with different polarities}

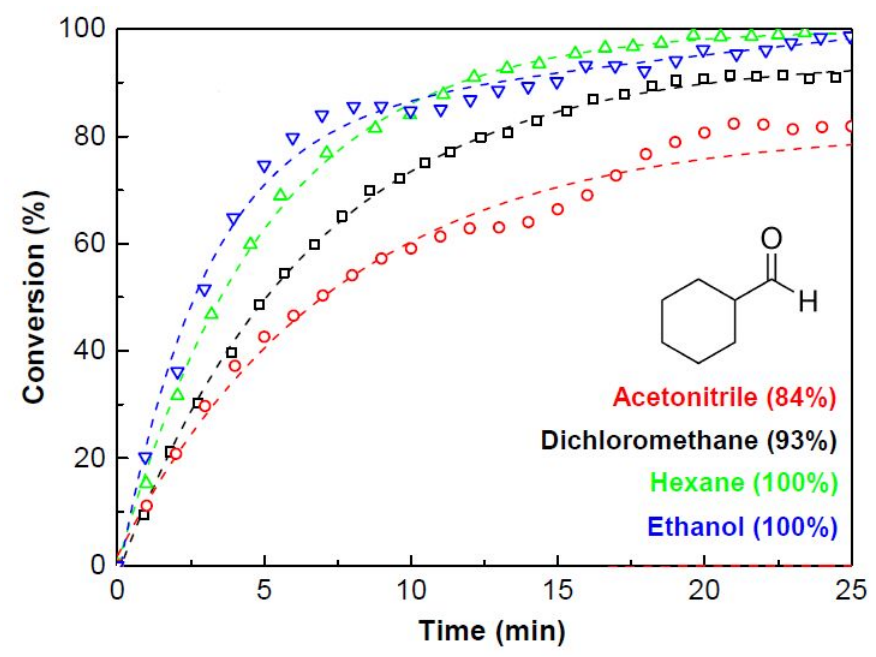

Figure S1 - Normalized trends for the capture of cyclohexanecarboxaldehyde by the Amb15-Iso resin, as measured by ATR-FTIR, in the different solvents. 

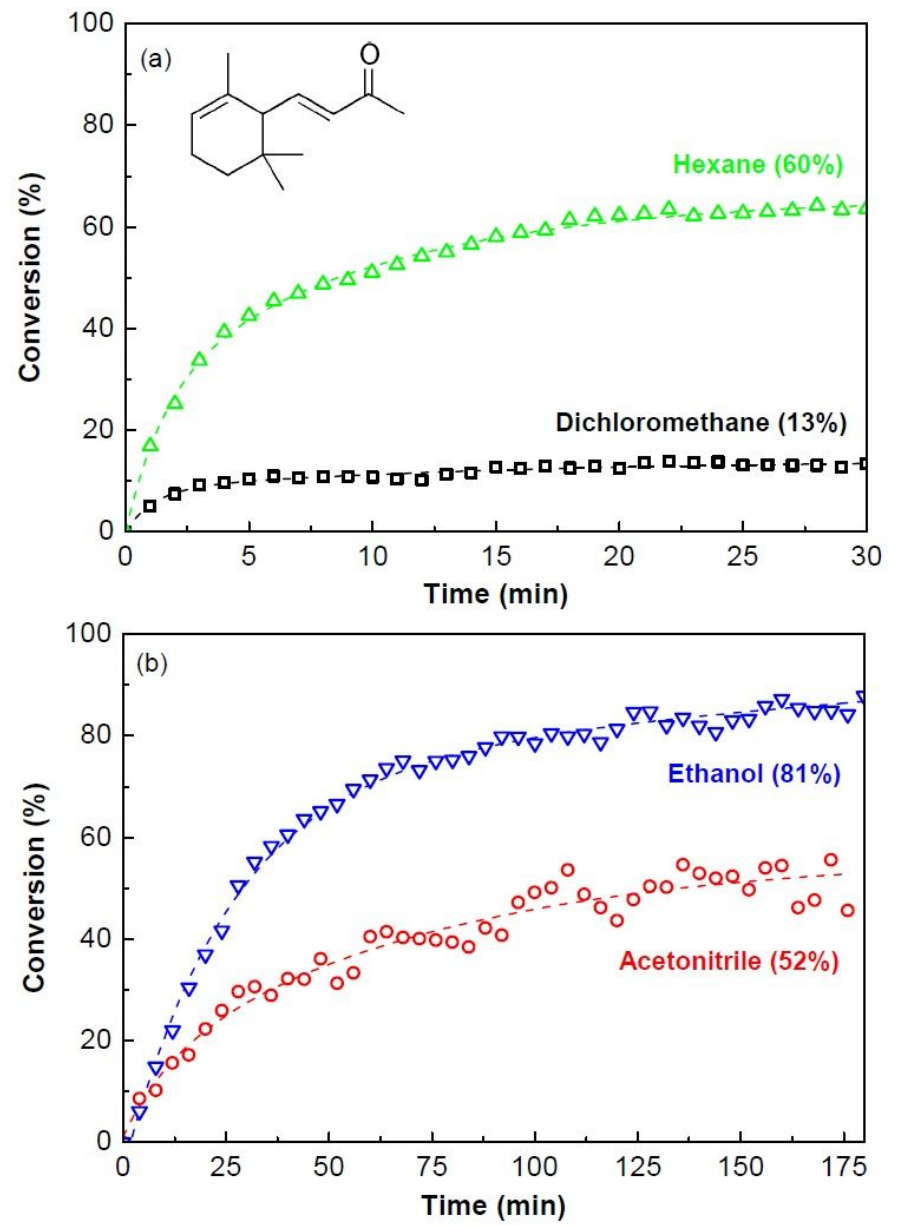

Figure S2 - Normalized trends for the capture of $\alpha$-ionone by the Amb15-Iso resin, as measured by ATRFTIR, in: (a) dichloromethane and hexane, with a stabilization time of $30 \mathrm{~min}$, and (b) acetonitrile and ethanol, with stabilization times of $180 \mathrm{~min}$. 

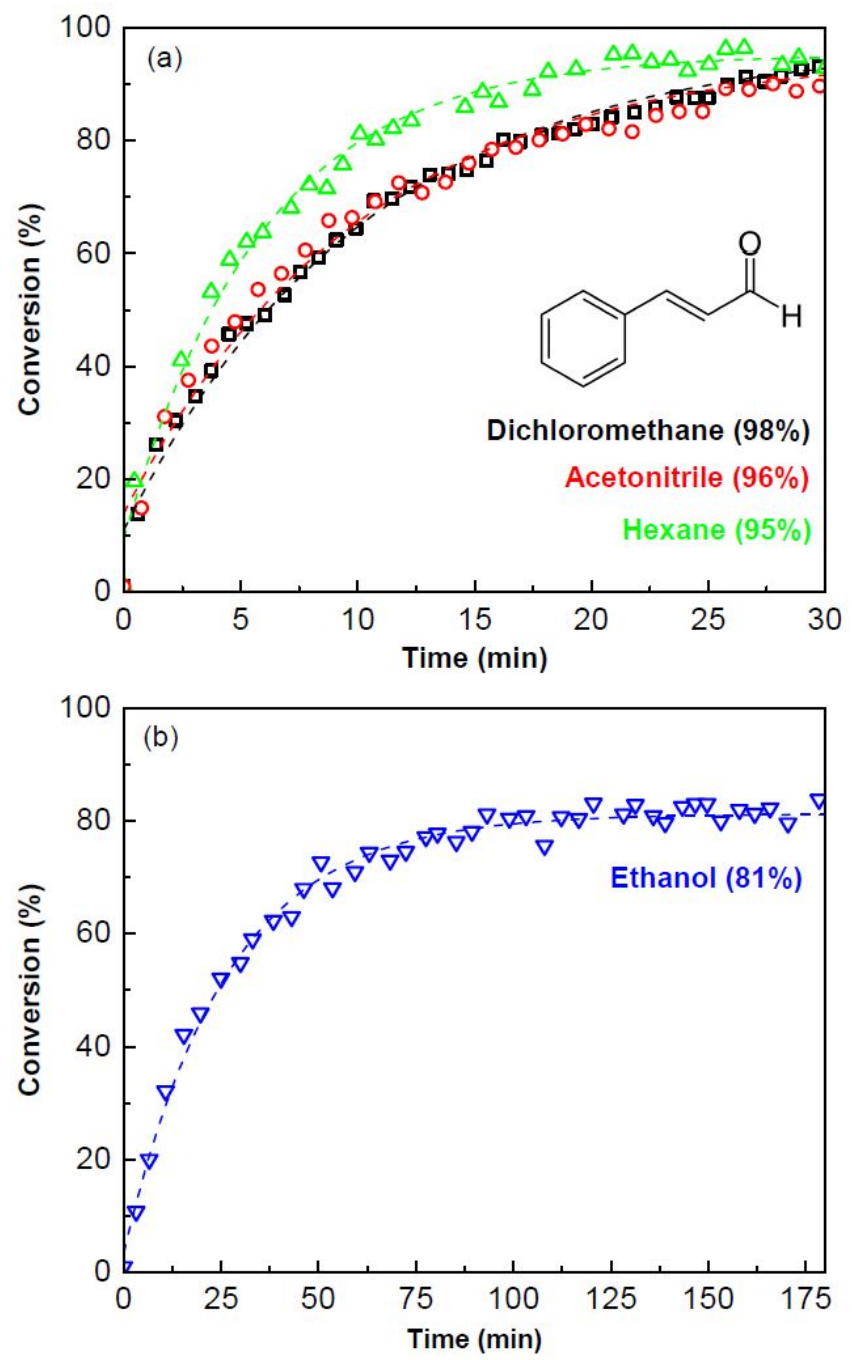

Figure S3 - Normalized trends for the capture of cinnamaldehyde by the Amb15-Iso resin, as measured by ATR-FTIR, in: (a) dichloromethane, acetonitrile and hexane, with stabilization times of $30 \mathrm{~min}$, and (b) ethanol, with a stabilization time of $180 \mathrm{~min}$. 


\section{Comparison between the reaction with the free and the bonded isoniazid}
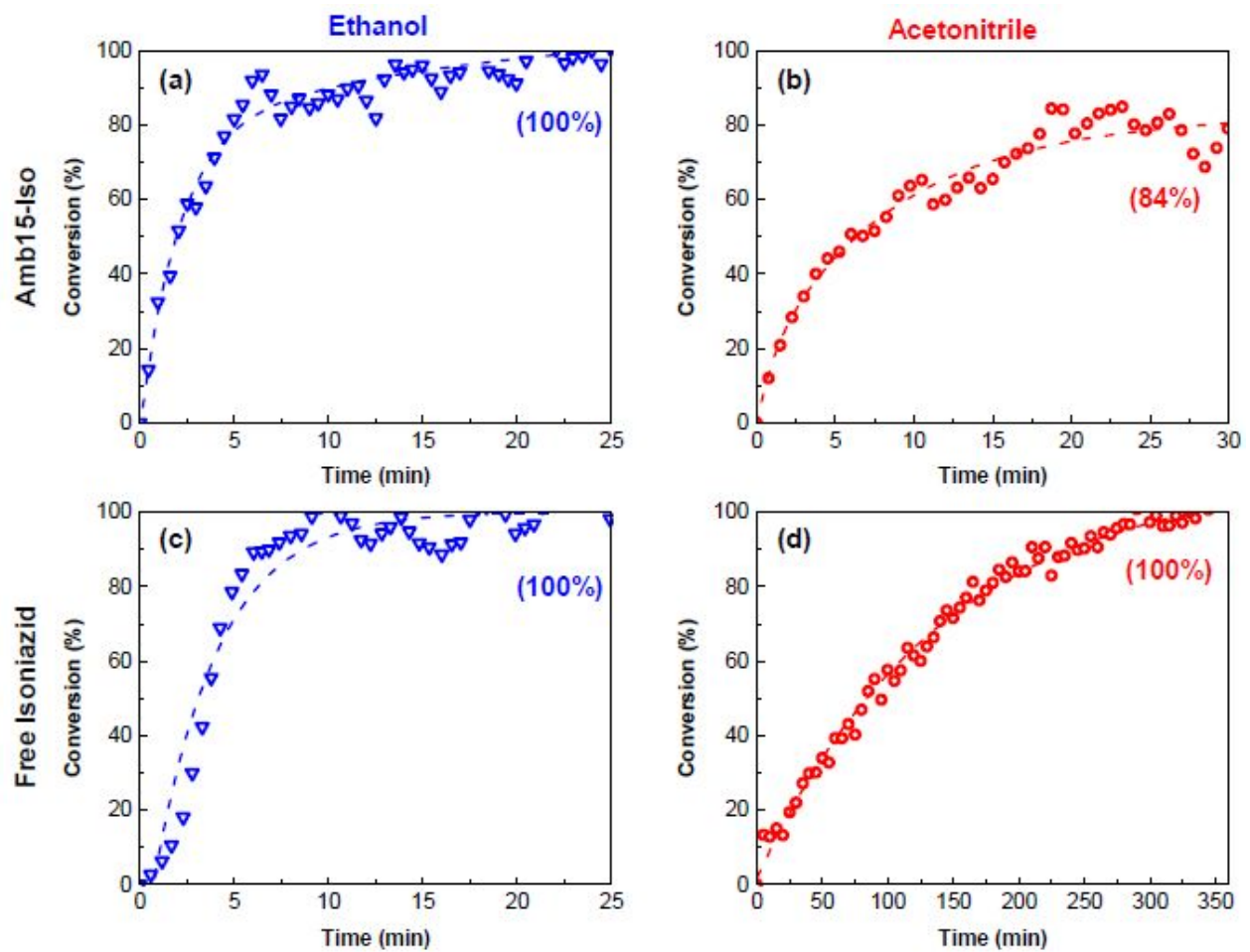

Figure S4 - Normalized trends, measured by ATR-FTIR, for the capture of cyclohexanecarboxaldehyde by the Amb15-Iso resin in (a) ethanol and (b) acetonitrile; and for the reaction between cyclohexanecarboxaldehyde and free isoniazid in (c) ethanol and (d) acetonitrile.
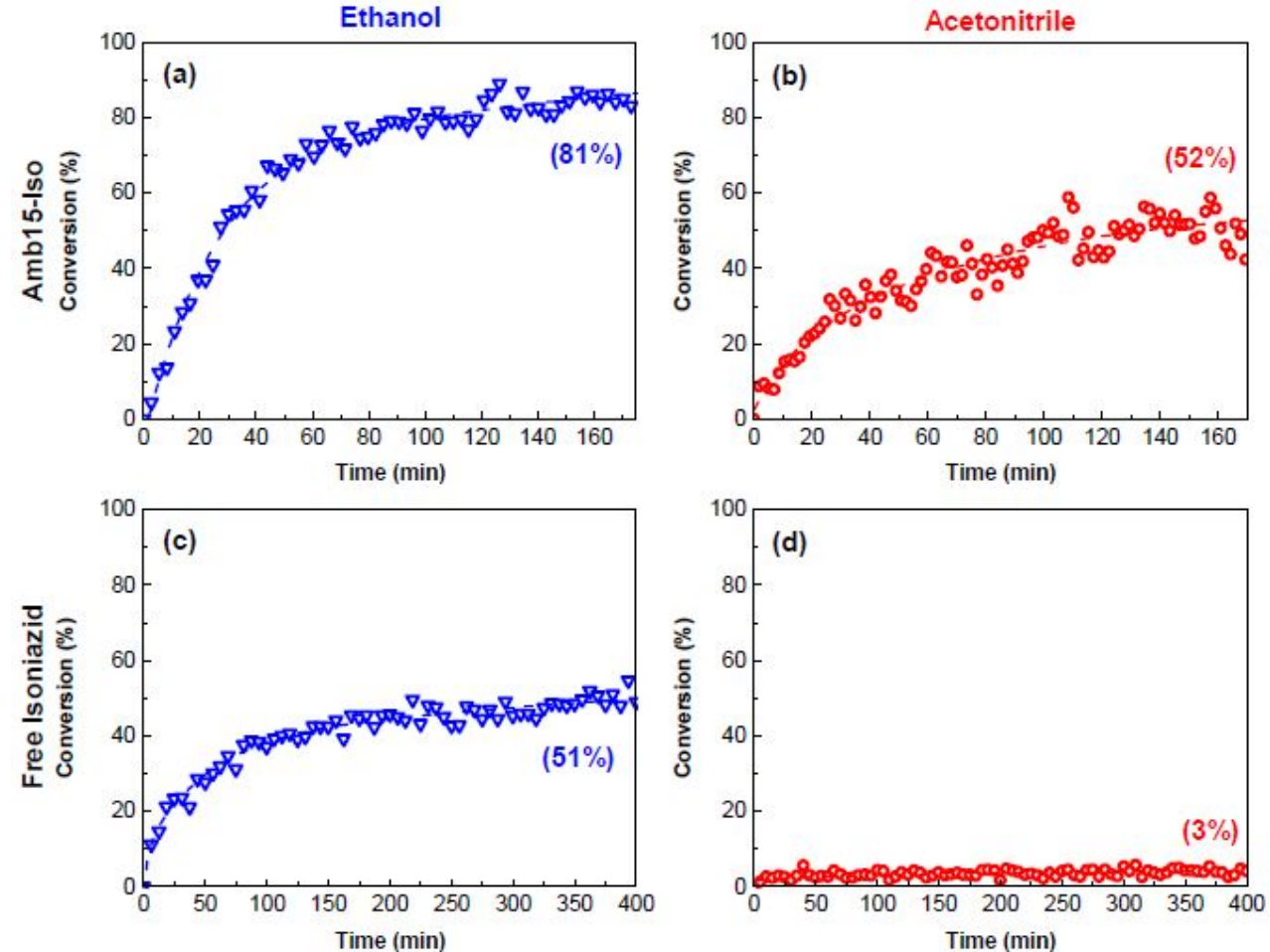

Figure S5 - Normalized trends, measured by ATR-FTIR, for the capture of $\alpha$-ionone by the Amb15-Iso resin in (a) ethanol and (b) acetonitrile; and for the reaction between $\alpha$-ionone and free isoniazid in (c) ethanol and (d) acetonitrile. 

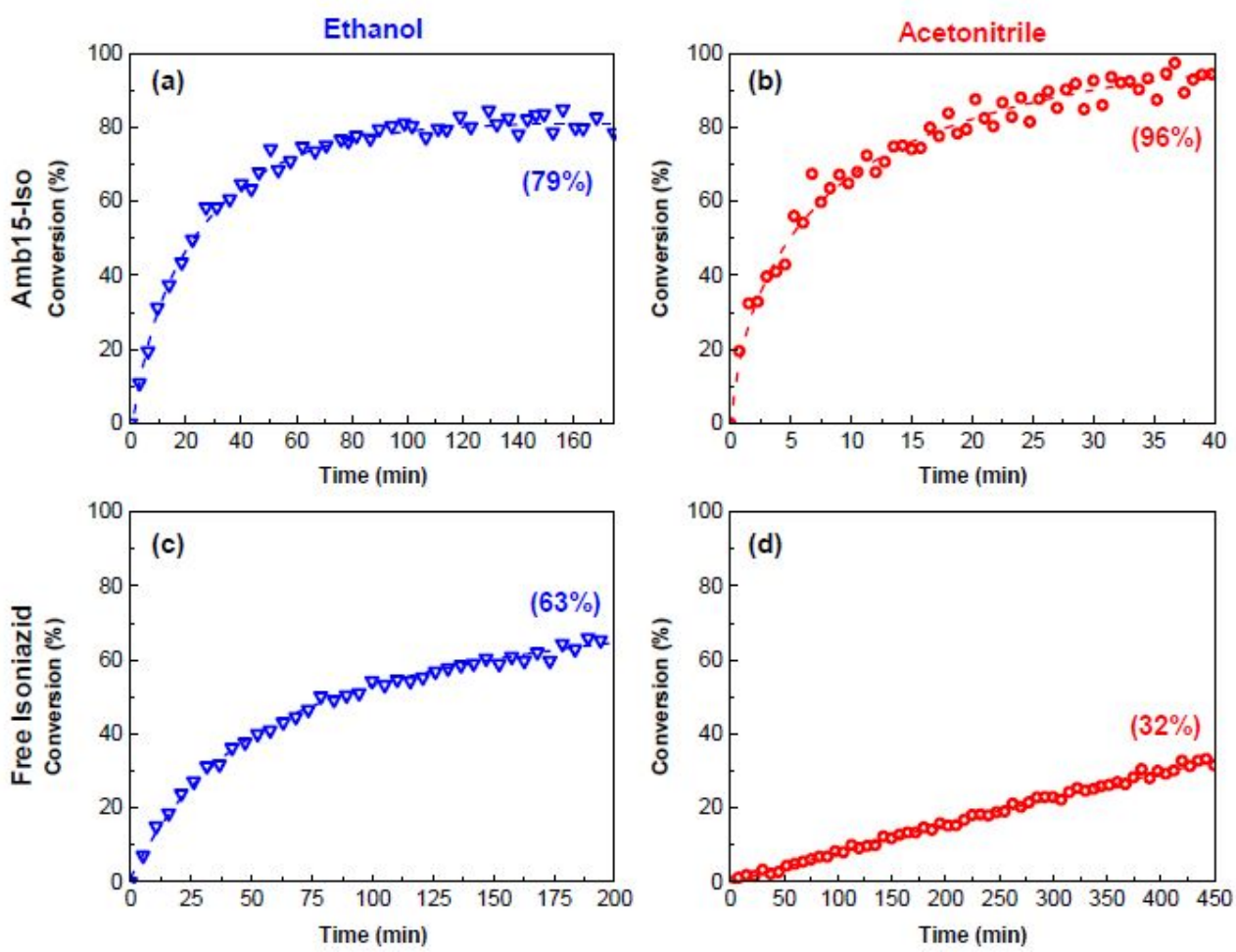

Figure S6 - Normalized trends, measured by ATR-FTIR, for the capture of cinnamaldehyde by the Amb15-Iso resin in (a) ethanol and (b) acetonitrile; and for the reaction between cinnamaldehyde and free isoniazid in (c) ethanol and (d) acetonitrile. 
GC-MS data for the reaction with the free isoniazid

(A) Reaction between Isoniazid and Cyclohexanone
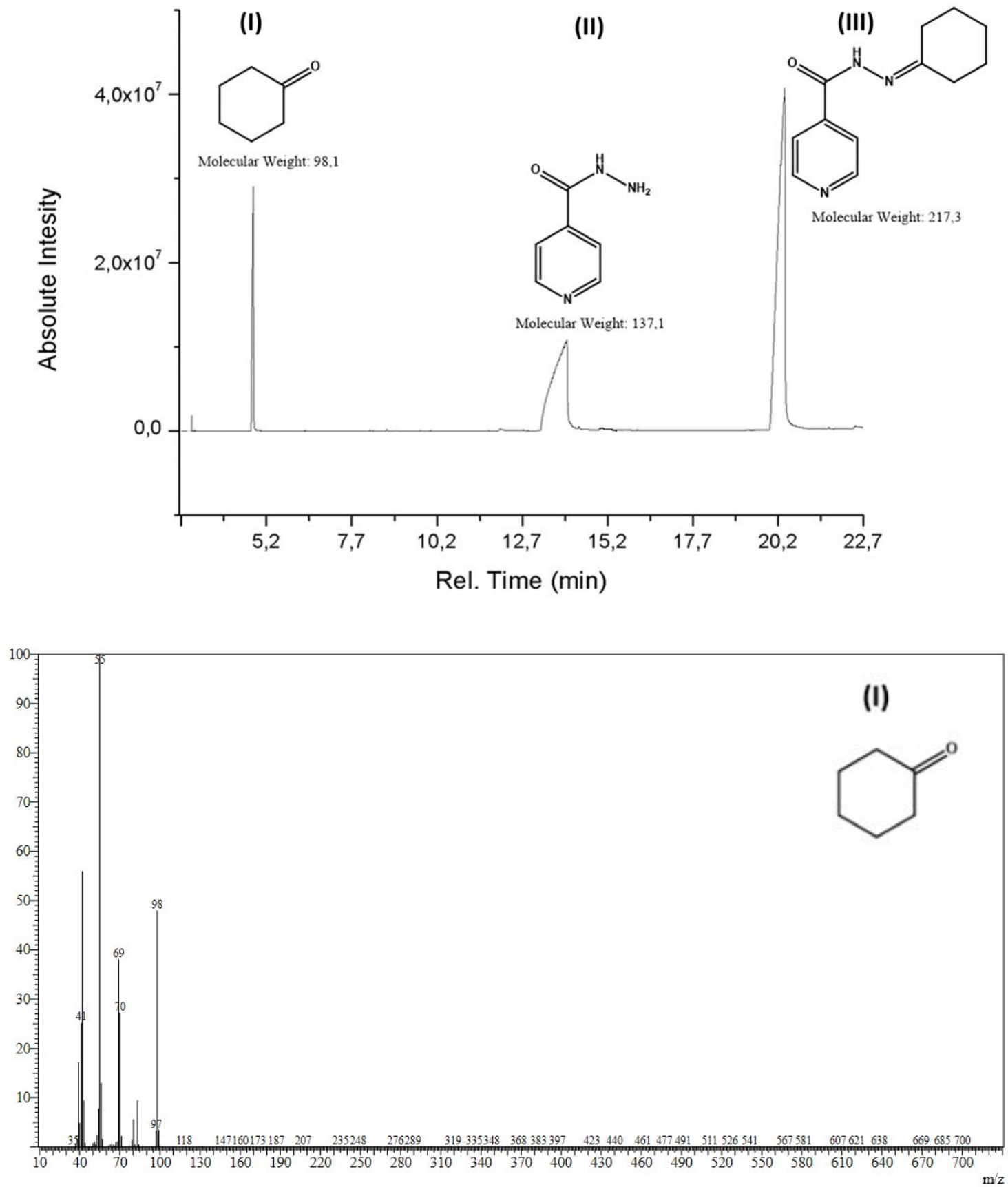

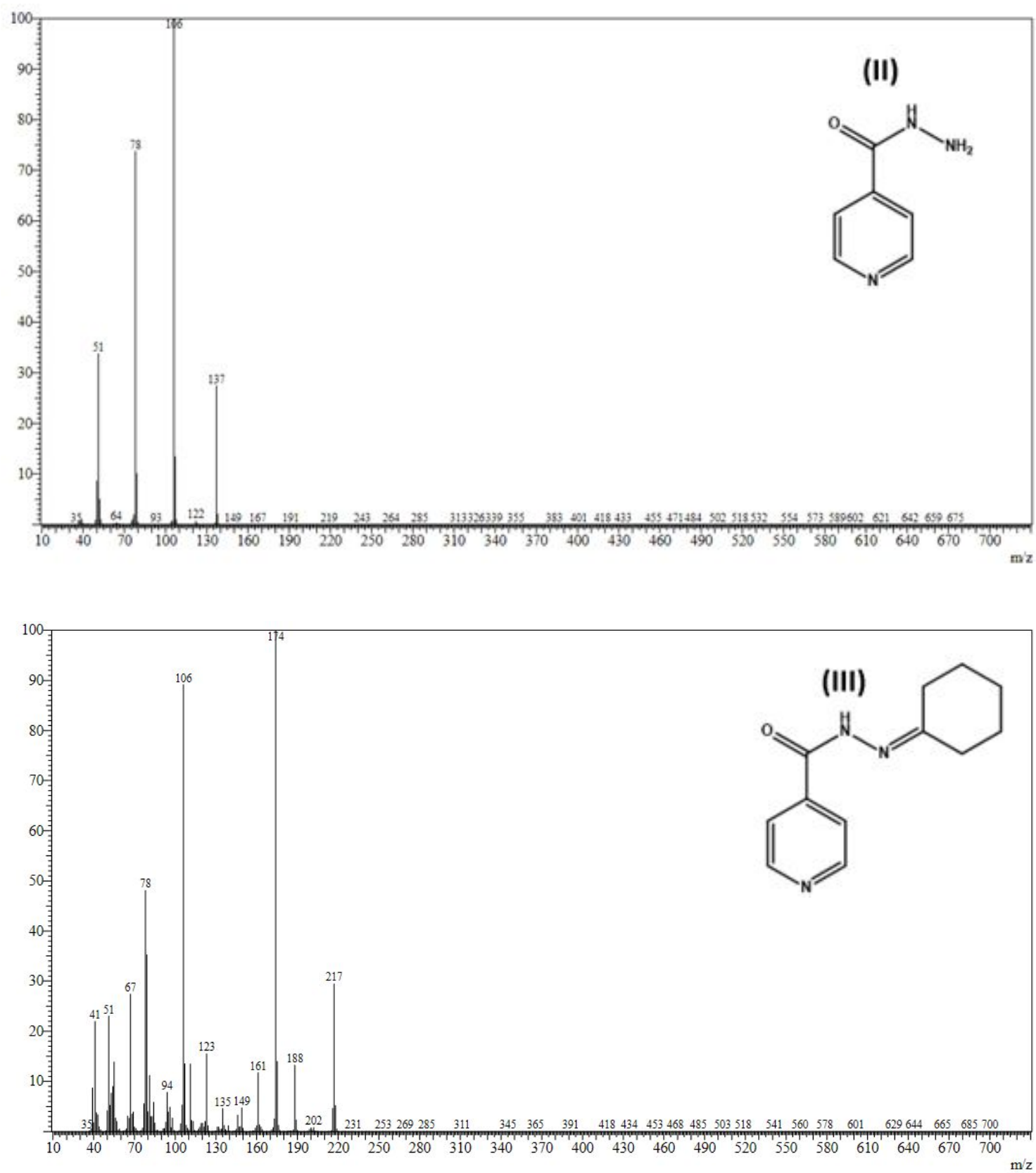

Figure S7 - GC-MS data measured for a sample of the reaction between free isoniazid and cyclohexanone at the end of the experiment 
(B) Reaction between Isoniazid and Cyclohexanecarboxialdehyde

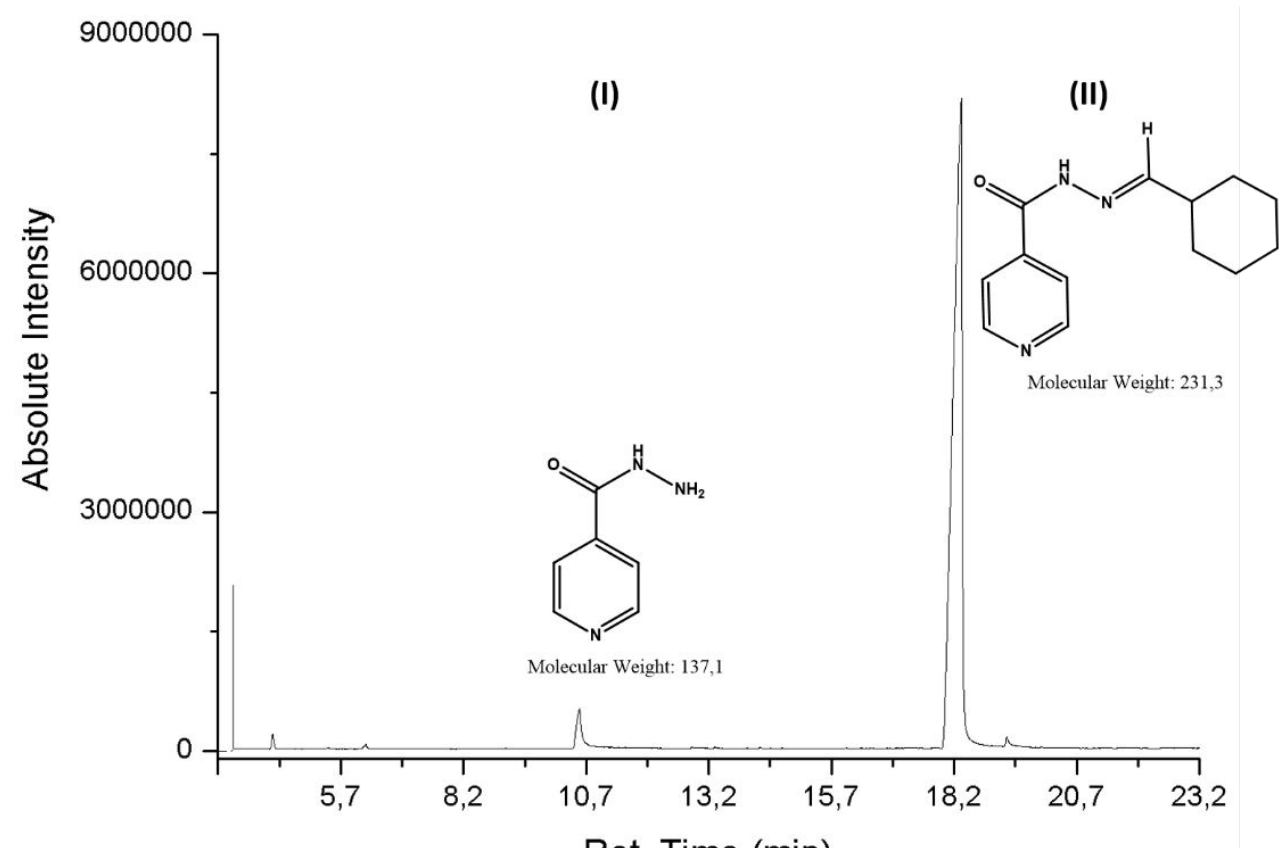

Ret. Time (min)

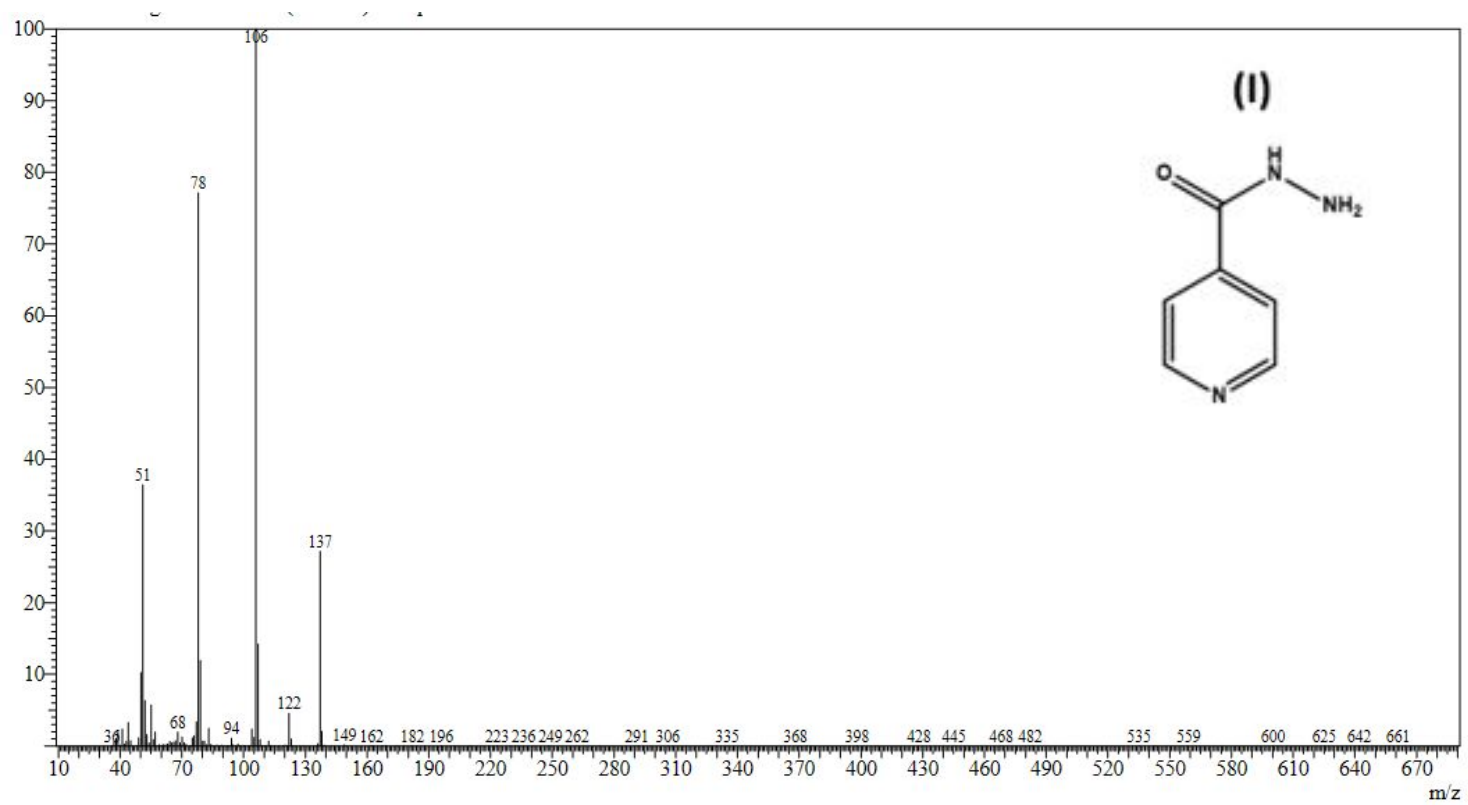




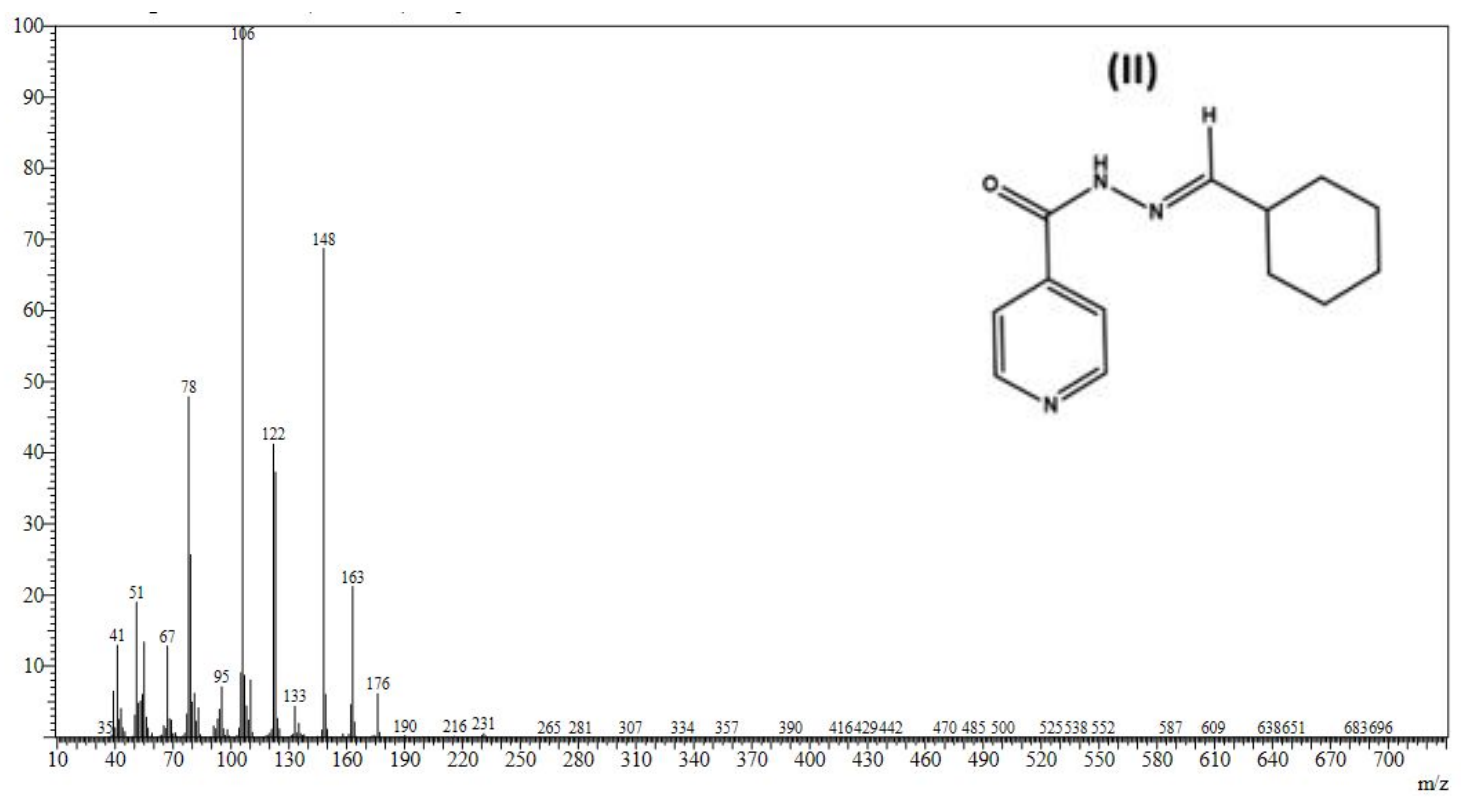

Figure S8 - GC-MS data measured for a sample of the reaction between free isoniazid and Cycloexanecarboxialdehyde at the end of the experiment 
(C) Reaction between isoniazid and $\alpha$-ionone
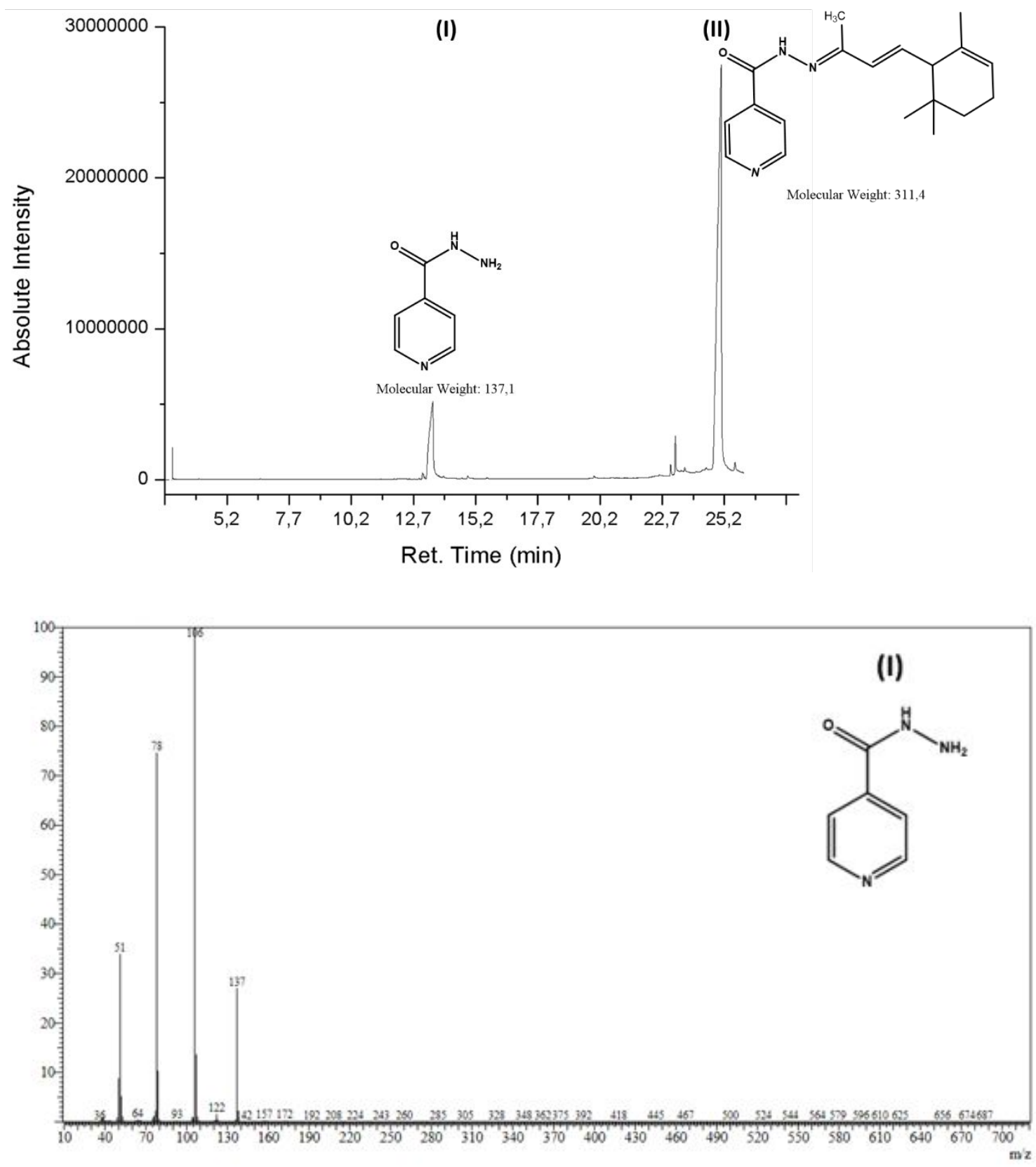


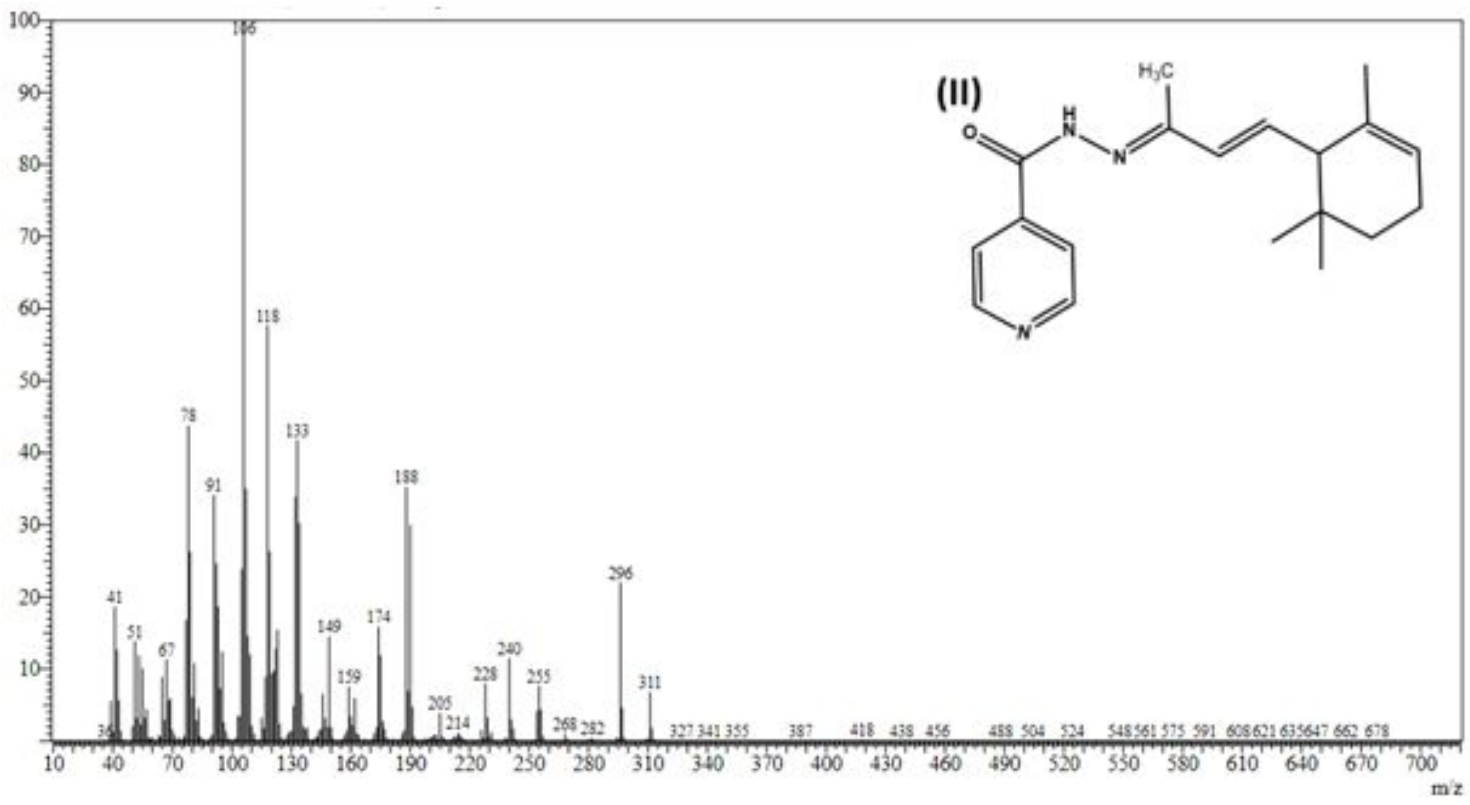

Figure S9-GC-MS data measured for a sample of the reaction between free isoniazid and $\alpha$-ionone at the end of the experiment 
(D) Reaction between Isoniazid and Cinnamaldehyde
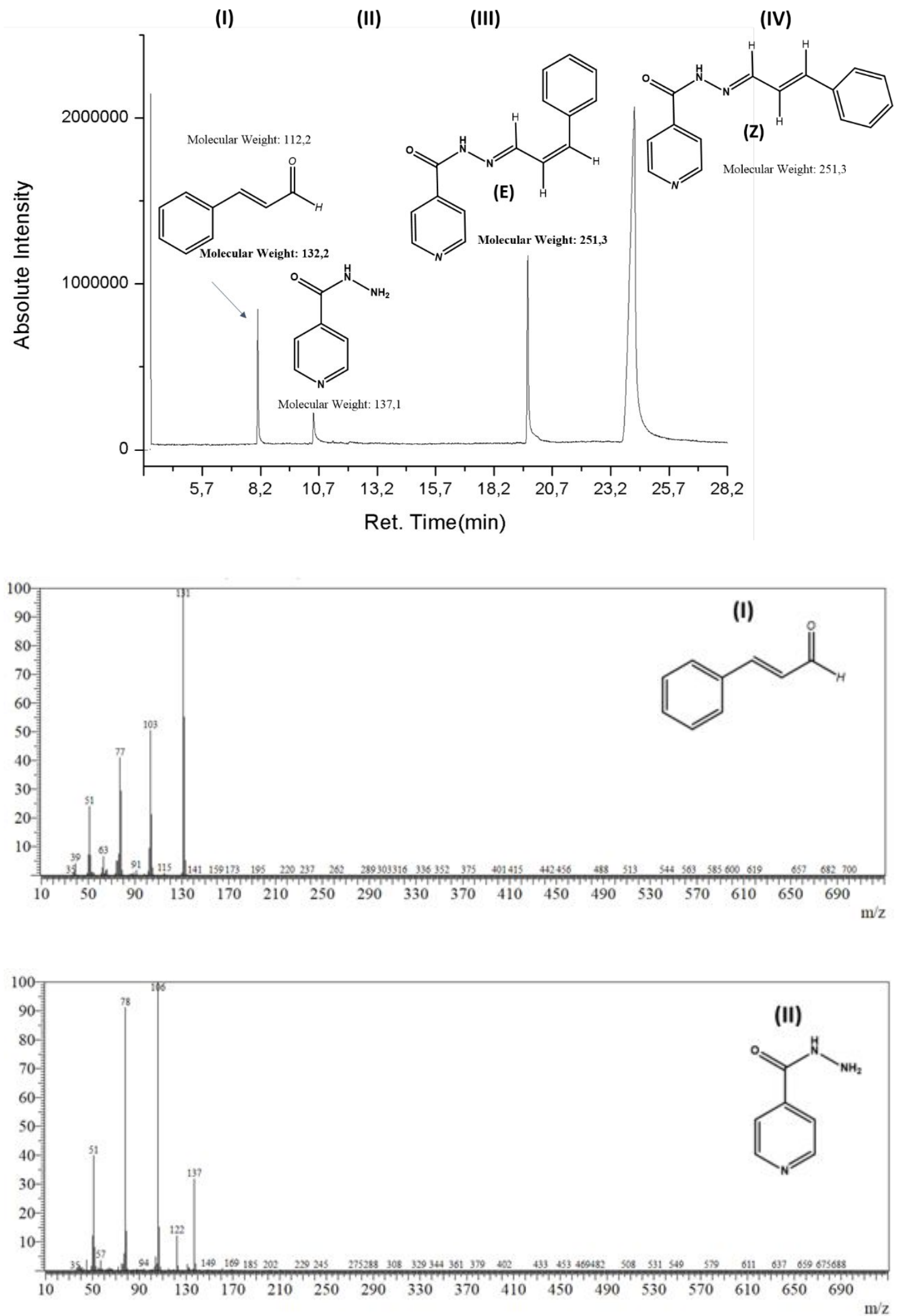

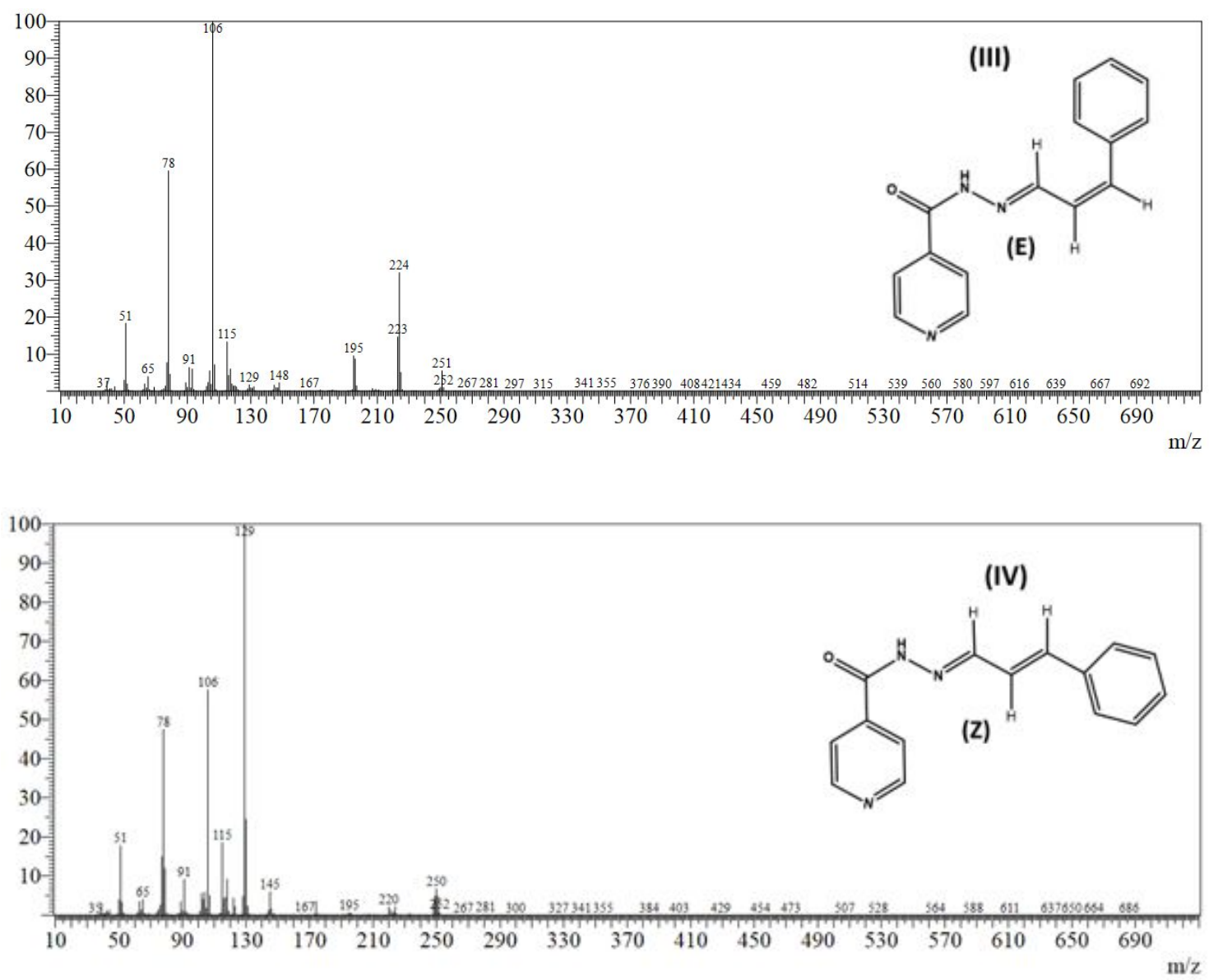

Figure S10 - GC-MS data measured for a sample of the reaction between free isoniazid and cinnamaldehyde at the end of the experiment 